\title{
Classification of multivariate data with a spiking neural network on neuromorphic hardware
}

\author{
Michael Schmuker ${ }^{1,2^{*}}$, Thomas Pfeil ${ }^{3}$, Martin P Nawrot ${ }^{1,2}$ \\ From Twenty Second Annual Computational Neuroscience Meeting: CNS*2013 \\ Paris, France. 13-18 July 2013
}

Progress in the field of computational systems neuroscience has uncovered a number of computational principles employed by nervous systems. At the same time neuromorphic hardware systems have evolved to a state where fast in silico implementations of complex neural networks are feasible. The current challenge is to identify and implement functional neural networks that enable neuromorphic computing to solve real world problems. Here, we present a generic spiking neural network for the supervised classification of multivariate data, a common problem in signal and data analysis. The network architecture was inspired by the data processing scheme of the olfactory system [1]. It has a three stage architecture. In the first stage, real-valued multivariate data is encoded into a bounded, positive firing-rate representation. The second stage removes correlation between input channels through lateral inhibition. Supervised training affects synaptic weights in the third stage, where classification of input patterns is performed.

We implemented and tested our network on the Spikey neuromorphic hardware system [2]. Our network performed on the same level as a Naïve Bayes classifier on several benchmark data sets. Our classifier network is an important proof-of-principle for a bio-inspired functional spiking network implemented on neuromorphic hardware performing a real-world computing task.

This study was funded by the DFG (SCHM2474/1-1, MS), the BMBF (01GQ1001D, MS and MN, 01GQ0941, $\mathrm{MN})$ and the European Union (243914, TP).

\footnotetext{
* Correspondence: m.schmuker@fu-berlin.de

${ }^{1}$ Theoretical Neuroscience, Institute of Biology, Freie Universität Berlin, Berlin, 14195, Germany

Full list of author information is available at the end of the article
}

\section{Author details}

${ }^{1}$ Theoretical Neuroscience, Institute of Biology, Freie Universität Berlin, Berlin, 14195, Germany. Bernstein Center for Computational Neuroscience Berlin, Berlin, 10115, Germany. ${ }^{3}$ Kirchhoff-Institute for Physics, Heidelberg University, Heidelberg, 69120, Germany.

Published: 8 July 2013

\section{References}

1. Schmuker M, Schneider G: Processing and classification of chemical data inspired by insect olfaction. PNAS 2007, 104:20285-9.

2. Pfeil T, Grübl A, Jeltsch $S$, Müller E, Müller P, Petrovici MA, Schmuker M, Brüderle D, Schemmel J, Meier K: Six networks on a universal neuromorphic computing substrate. Frontiers Neuromorph Eng 2013, 7:11.

doi:10.1186/1471-2202-14-S1-P290

Cite this article as: Schmuker et al: Classification of multivariate data with a spiking neural network on neuromorphic hardware. $B M C$ Neuroscience 2013 14(Suppl 1):P290.
Submit your next manuscript to BioMed Central and take full advantage of:

- Convenient online submission

- Thorough peer review

- No space constraints or color figure charges

- Immediate publication on acceptance

- Inclusion in PubMed, CAS, Scopus and Google Scholar

- Research which is freely available for redistribution

Submit your manuscript at www.biomedcentral.com/submit
() Biomed Central
C Biomed Central

(c) 2013 Schmuker et al; licensee BioMed Central Ltd. This is an Open Access article distributed under the terms of the Creative Commons Attribution License (http://creativecommons.org/licenses/by/2.0), which permits unrestricted use, distribution, and reproduction in any medium, provided the original work is properly cited. 